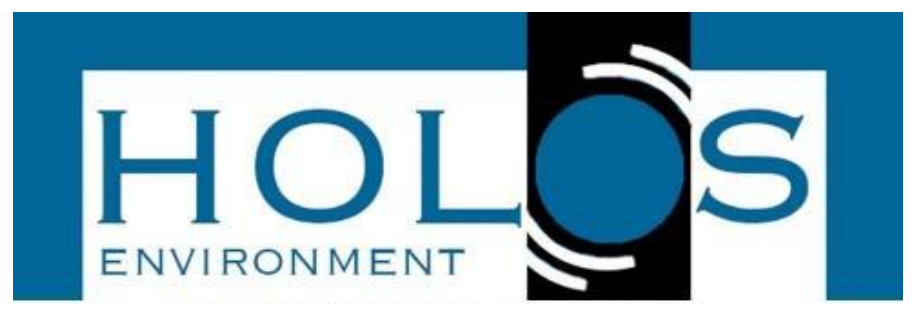

\title{
MAPEAMENTO DAS CLASSES DO CADASTRO AMBIENTAL RURAL (CAR) DE IMÓVEIS RURAIS FAMILIARES E NÃO FAMILIARES NAS CHAPADAS E GROTAS DO ALTO JEQUITINHONHA-MG
}

\section{MAPPING THE CLASSES OF RURAL ENVIRONMENTAL REGISTRATION (CAR) IN FAMILY AND NON-FAMILY RURAL PROPERTIES IN PLACES AND GROUPS OF ALTO JEQUITINHONHA-MG}

\author{
Leonardo França da Silva1; Marcos Antônio Pereira da Fonseca Maltez²; Emilia Pereira Fernandes \\ da Silva ${ }^{3}$; Kamila Cristina de Credo Assis ${ }^{4}$; Maria Clara Lelles Moreira Begueline ${ }^{4}$; \\ Bruna Nogueira Rezende ${ }^{4}$
}

Artigo recebido em: 06/08/2020 e aceito para publicação em: 02/02/2021.

DOI: http:/dx.doi.org/10.14295/holos.v21i1.12414

\begin{abstract}
Resumo: Com o avanço da tecnologia da informação e o advento das geotecnologias, quanto maior o número de informações globais, regionais e locais, maior é a possibilidade de sucesso do planejamento. o presente artigo teve como objetivo sobrepor informações dos imóveis rurais, áreas de vegetação preservada e nascentes em áreas da agricultura familiar e não familiar, na região das chapadas e grotas do Alto Jequitinhonha, utilizando como banco de dados as informações disponibilizadas pelo SICAR (Sistema Nacional de Cadastro Ambiental Rural), IBGE (Instituto Brasileiro de Geografia e Estatistica e informações topográficas fornecidas pelo SRTM. Para o processamento das informações foi utilizado software de geoprocessamento ArcGis 10.3. A sobreposição das informações se deu a partir das ferramentas do próprio software. Foi possivel que a região do Alto Jequitinhonha é uma região de agricultura familiar tradicional e numerosa, onde o relevo formado por chapadas e grotas determinou os diferentes processos de ocupação e uso dos solos na região. A chegada de grandes empreendimentos, principalmente o reflorestamento com eucalipto, alterou drasticamente a dinâmica da região, a partir dos dados do CAR foi possível observar as mudanças no uso e posse da terra, recursos hídricos e vegetação nativa.
\end{abstract}

Palavras-chave: Agricultura familiar. Desenvolvimento Rural. CAR.

\begin{abstract}
With the advancement of information technology and the advent of geotechnologies, the greater the number of global, regional and local information, the greater the possibility of successful planning. This article aimed to superimpose information from rural properties, areas of preserved vegetation and springs in areas of family and non-family agriculture, in the region of the Alto Jequitinhonha Chapadas and Grotas, using as a database the information provided by SICAR (National System of the Rural Environmental Registry), IBGE (Brazilian Institute of Geography and Statistics and topographic information provided by SRTM. For processing the information, ArcGis 10.3 geoprocessing software was used. The information was overlapped using the software's own tools. It was possible that the region of Alto Jequitinhonha is a region of traditional and numerous family farming, where the relief formed by chapadas and grotas determined the different processes of occupation and use of the soils in the region. The arrival of large enterprises, mainly the reforestation with eucalyptus, altered dramatically the dynamics of the region, from the data $s$ of the CAR it was possible to observe changes in the use and possession of land, water resources and native vegetation.
\end{abstract}

\footnotetext{
${ }^{1}$ Universidade Federal de Viçosa (UFV), Viçosa, MG. E-mail: (franca.leonardo@yahoo.com.br)

2 Universidade Federal do Rio Grande do Sul (UFRGS), Porto Alegre, RS. E-mail: ( marcos.maltez@biocitrus.com.br)

${ }_{3}^{3}$ Universidade Federal de Minas Gerais (UFMG) Belo Horizonte, MG / Universidade Estadual de Montes Claros (UNIMONTES), Montes Claros, MG. E-mail: (emiliafernandes pdi@hotmail.com).

4 Faculdade Ciências Agronômicas (FCA -UNESP), São Paulo, SP. E-mails: (k.assis@unesp.br, mariaclara begueline@hotmail.com, bbrunarezende@hotmail.com)
} 


\section{INTRODUÇÃO}

As Chapadas e Grotas do Alto Jequitinhonha fazem parte da mesorregião do Vale do Jequitinhonha, região que recebe esse nome por ter seu relevo caracterizado pela presença de extensas chapadas, cortadas por profundas grotas. (GALIZONI, 2002; RIBEIRO et al., 2007). Essas áreas encontra na zona de transição entre o cerrado e a mata atlântica o uso e ocupação dos solos na região foram regidos pela disponibilidade dos recursos naturais. A região compreende 19.558,30 km² e é composta por 20 municípios mineiros. Segundo dados do Instituto Brasileiro de Geografia e Estatística (IBGE, 2019) a região possui 270 mil habitantes sendo que $41 \%$ vivem na zona rural.

O uso e ocupação dos solos na região foram regidos pela disponibilidade dos recursos naturais, as grotas apresentam uma fertilidade natural maiores e encontram próximas aos cursos de água, são consideradas pelos agricultores terras boas para 0 cultivo de alimentos voltados para alimentação básica tais como: arroz, feijão, mandioca e milho. Já As chapadas possuem fertilidade natural menor, porém, apresentam alta quantidade de forragem nativa e produtos extrativista, e são utilizadas como recurso comum para criação de gado extensivamente. Assim, permaneceu a região até a década de 1970, quando no período da ditadura militar se tornou foco de processos de desenvolvimento (RIBEIRO; GALIZONI, 2000; GALIZONI, 2002; SILVA, 2014).

Uma importante ferramenta no monitoramento de áreas com enfoque na preservação ambiental é O Cadastro Ambiental Rural (CAR) este um registro eletrônico e obrigatório para todos os imóveis rurais do Brasil, criado pela Lei oㅜ 12.651/2012 no âmbito do Sistema Nacional de Informação sobre Meio Ambiente - SINIMA. O CAR constitui um importante instrumento para o planejamento agrícola, ambiental e econômico para o Brasil (BRASIL, 2012).

O principal objetivo do CAR é integrar as informações ambientais das propriedades e posses rurais, referentes a Área de Preservação Permanente (APP), Reserva Legal (RL), remanescentes de florestas e demais formas de vegetação nativa. A partir das informações contidas no CAR é possível o controle, monitoramento e combate ao desmatamento das florestas e vegetação nativa do Brasil, bem como para o planejamento ambiental e econômico dos imóveis rurais. A inscrição no CAR e requisito obrigatório para acessar 
diversos programas, benefícios e autorizações, como: linhas de crédito, seguro e financiamento agrícola.

Uma das principais inovações implementadas pelo CAR, foi à utilização efetiva do geoprocessamento como forma registro, possibilitando a disponibilização dos dados cartografados, qualificados e quantificados dos imóveis rurais.

Com o avanço da tecnologia da informação e o advento das geotecnologias, quanto maior o número de informações globais, regionais e locais, maior é a possibilidade de sucesso do planejamento. As geotecnologias possibilitaram a associar qualquer tipo de informação, mas principalmente as ambientais, ao espaço geográfico por meio de imagens de satélite e fotografias aéreas, o Global Positioning System (GPS) e os Sistemas de Informações Geográficas (SIGs). A obtenção de mapas com rapidez, qualidade e precisão, além do acesso a diferentes bancos de dados, transformou o geoprocessamento em uma importante ferramenta no estudo sobre o meio ambiente (SILVA, 2004; VOLPATO; ALVES; VIEIRA, 2008).

Com base neste exposto, o presente artigo teve como objetivo sobrepor informações dos imóveis rurais, áreas de vegetação preservada e nascentes em áreas da agricultura familiar e não familiar, na região das chapadas e grotas do Alto Jequitinhonha, utilizando como banco de dados as informações disponibilizadas pelo SICAR (Sistema Nacional de Cadastro Ambiental Rural), IBGE (Instituto Brasileiro de Geografia e Estatistica e informações topográficas fornecidas pelo SRTM.

\section{MATERIAL E MÉTODOS}

Como fonte de dados foram utilizadas as informações disponíveis no SICAR (2017) os dados disponíveis pelo IBGE e as informações topográficas contidas no SRTM (16S42ZN e 16S45-ZN) com resolução de 90 metros. Para o processamento das informações foi utilizado software de geoprocessamento ArcGis 10.3. O processamento de dados se deu a partir da metodologia proposta pelo Grupo de Inteligência Territorial Estratégica (GITE) da Empresa Brasileira de Agropecuária (EMBRAPA) (MIRANDA et al., 2016) que determinou a junção, exclusão e sobreposição de shapes e informações contidas nas três fontes de dados.

Para a realização do estudo foram selecionados dentro do Alto do Jequitinhonha os municípios de Turmalina, Minas Novas, Itamarandiba, Veredinha, Capelinha, Carbonita e 
Aricanduva, como mostra a Figura 1, devido as características homogeneas como o relevo e desenvolvimento econômico-social.

A classificação da declividade seguiu a metodologia em classes, classificação proposta pela EMBRAPA (1995), sendo que toda propriedade com área menor ou igual a 4 módulos fiscais $(\leq 4)$, foi considerada agricultura familiar; e, áreas acima de 4 módulos fiscais ( $>4$ ), foram consideradas como não familiares. Os limites dessas duas classes foram utilizados para o recorte da vegetação preservada e nascentes, também para sobrepor os imóveis rurais sobre o mapa de declividade.

Figura 1 - Localização da área de estudo, Alto Jequitinhonha-MG

\section{LOCALIZAÇÃO DA ẢREA DE ESTUDO}

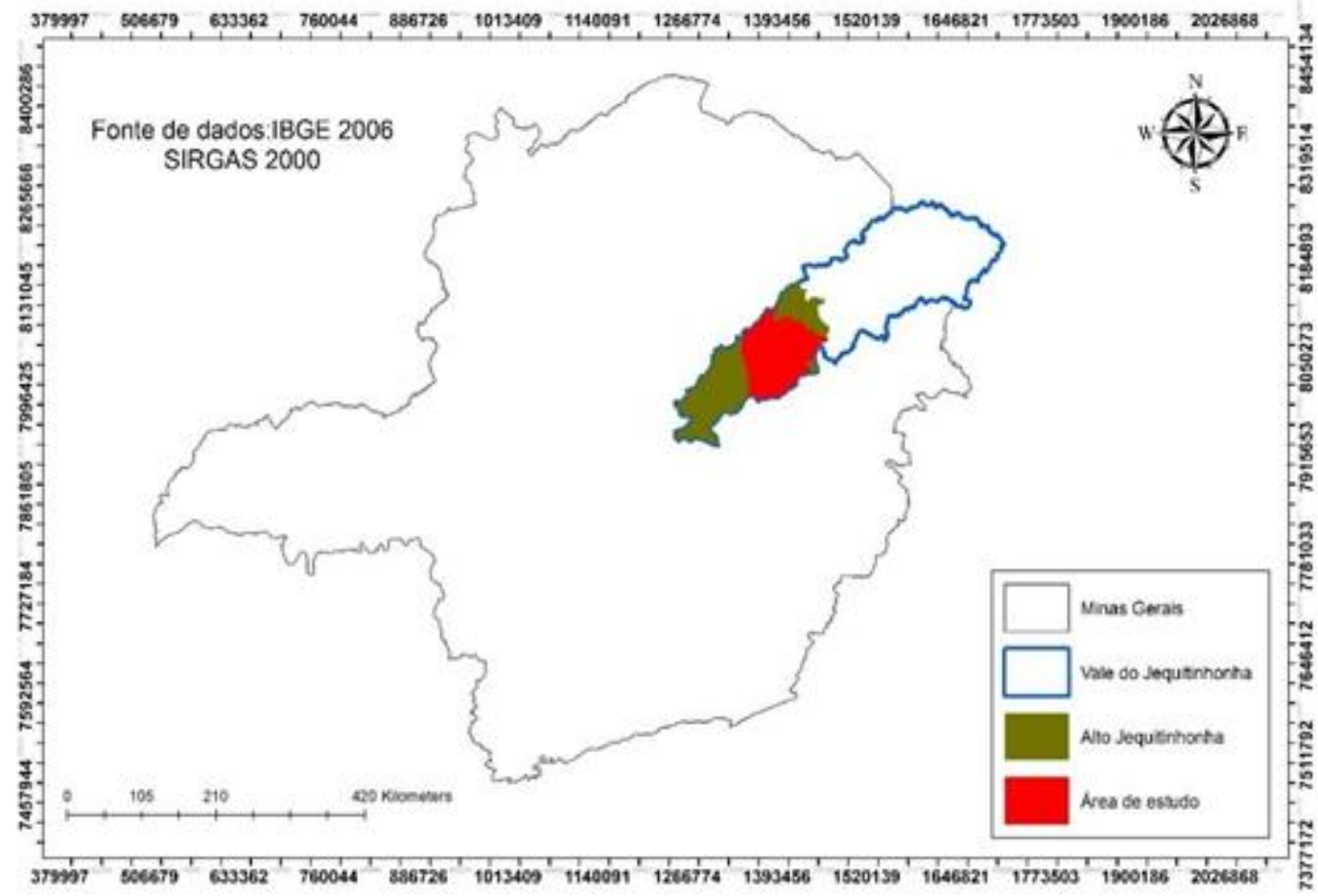

Fonte: Autores (2017)

\section{RESULTADOS E DISCUSSÃO}

A distribuição dos imóveis rurais e sua qualificação em agricultura familiar e não familiar é apresentada na Figura 2. As grandes propriedades representaram a maior porção de terra. Nessas áreas é possível observar principalmente a produção em larga escala de eucalipto. Já a agricultura familiar encontrou-se pulverizada no entorno dessas grandes áreas, com a produção de alimentos direcionada ao autoconsumo e venda do excedente, e que possuem imóveis menores, variando entre 1 e 4 módulos fiscais. 
Figura 2 - Distribuição dos imóveis rurais em agricultura familiar e não familiar DISTRIBUIÇĀO DOS IMÓVEIS RURAIS

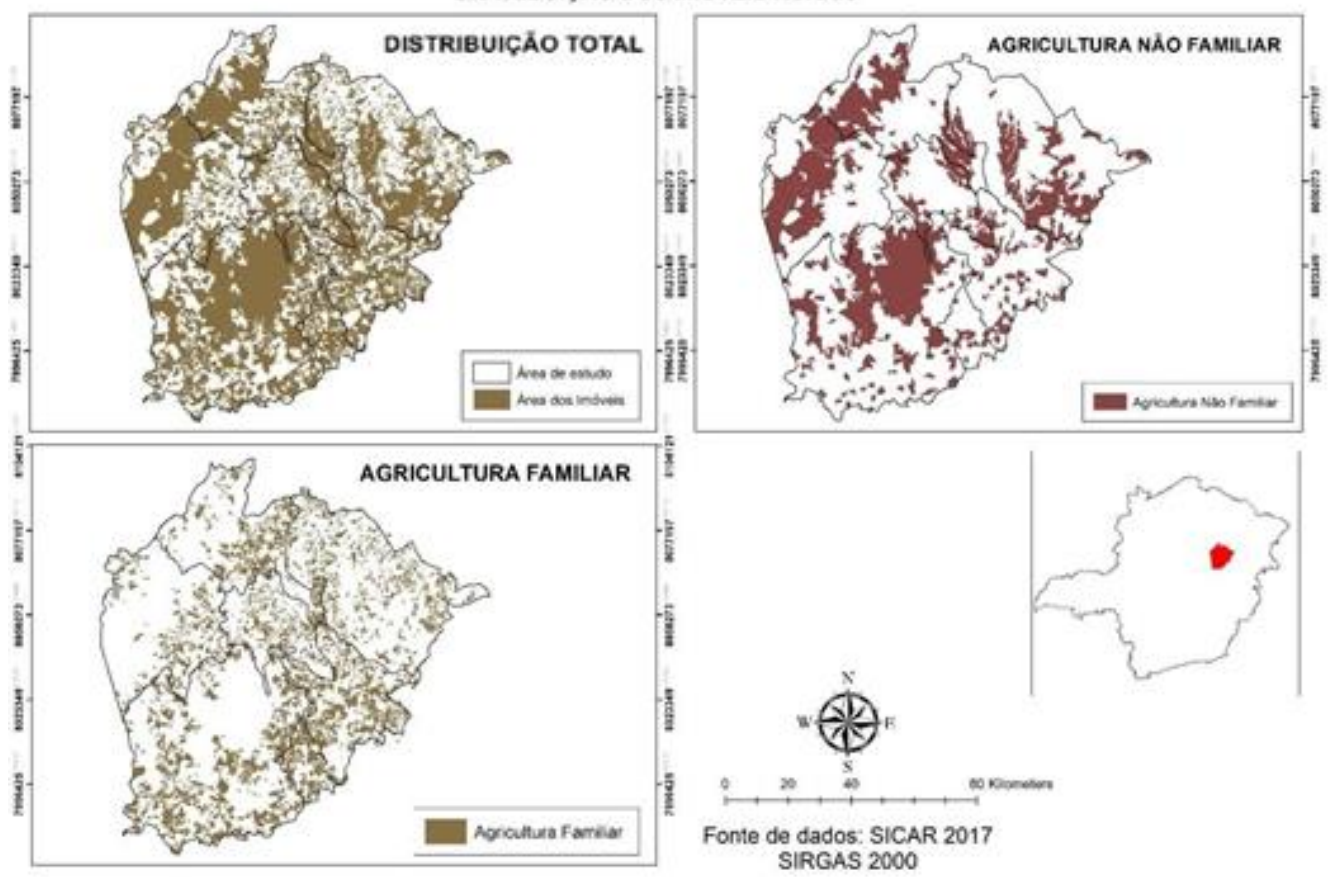

Fonte: Autores (2017)

$\mathrm{Na}$ Tabela 1 são apresentados os dados quantitativos dos imóveis rurais totais e também da distribuição entre agricultura familiar e não familiar. Apesar da agricultura familiar representar 96\% (8460) dos imóveis rurais da região, essa ocupa apenas $46 \%$ do total da área (324.982,00). Enquanto a agricultura que não familiar, representa apenas $4 \%$ (332) do total dos imóveis rurais, e ocupa um total de $54 \%$ da área (386.819,00 ha).

Tabela 1 - Dados Quantitativos dos Imóveis Rurais das cidades de Turmalina, Minas Novas, Itamarandiba, Veredinha, Capelinha, Carbonita e Aricanduva

\begin{tabular}{ccccc}
\hline Tipo de Imóvel & $\begin{array}{c}\text { Quantidade de } \\
\text { imóveis }\end{array}$ & $\begin{array}{c}\text { Área } \\
\text { (hectares) }\end{array}$ & $\begin{array}{c}\text { Ocupação } \\
\text { da área (\%) }\end{array}$ & $\begin{array}{c}\text { Imóveis } \\
\text { rurais (\%) }\end{array}$ \\
\hline $\begin{array}{c}\text { Agricultura } \\
\text { familiar }\end{array}$ & 8460 & $324.982,00$ & $46 \%$ & $96 \%$ \\
$\begin{array}{c}\text { Agricultura não } \\
\text { familiar }\end{array}$ & 332 & $386.819,00$ & $54 \%$ & $4 \%$ \\
$\quad$ Total & 8792 & $711.801,00$ & $100 \%$ & $100 \%$
\end{tabular}

Fonte: (Autores, 2017)

Esse processo de acumulação fundiária é fruto dos projetos de desenvolvimento que ocorreram na região durante a década de 1960-1970. A região das chapadas e grotas tinha na agricultura familiar e tradicional sua base econômica, muito distante do paradigma de desenvolvimento que prezado na época, sendo considerada então uma região estagnada e parada no tempo (CODEVALE, 1967; LEITE, 2010). 
Essa interpretação feita pelos formuladores de políticas públicas rendeu na época ao Alto Jequitinhonha os nomes de "Vale da Miséria e África Brasileira" (CALIXTO, 2006). O que ajudou a legitimar a implantação da silvicultura na região, que tinha o intuito de levar "emprego, desenvolvimento e renda" para a população local. Porém, o que ocorreu foi o aumento da desigualdade social na região, principalmente, pelo aumento do preço da terra e da especulação financeira (SOUZA, 2014; RIBEIRO et al., 2007; RIBEIRO \& GALIZONI, 2003).

As chapadas eram consideradas terras "vazias" e que deveriam ser incorporados ao desenvolvimento da região (CODEVALE, 1967; LEITE, 2010), essas apesar de terem fertilidade natural menor, apresentam ótima declividade para silvicultura (0-13\%) (RIBEIRO; GALIZONI, 2000; SOUZA, 2014). Com a modernização da agricultura, o problema da baixa fertilidade e acidez do solo foram resolvidos, possibilitando assim, a implantação da silvicultura na região (CALIXTO, 2006). A agricultura familiar que inicialmente ocupou as grotas teve seus terrenos assegurados, principalmente pela resistência e por estarem em uma região onde o tripé da modernização da agricultura (adubo, veneno e trator) em razão da declividade não conseguiriam ser implementados, já que a declividade (20-100\%) das grotas não possibilitaria o avanço deste modelo de exploração na área (MAZOYER, 2010).

Na Figura 3 é apresentada a distribuição dos imóveis sobre a declividade. As áreas de chapada, ou seja, áreas de baixa declividade, atualmente são ocupadas pelas grandes propriedades no monocultivo do eucalipto. As áreas mais íngremes apresentam o maior volume de pequenas propriedades.

A privatização das chapadas legou aos agricultores familiares o uso somente das grotas, diminuindo seu terreno para cria de gado e aumentando a desigualdade social da região. A quantidade média de área ficou em 38,41 ha para a agricultura familiar, enquanto a agricultura não familiar tem em média 1165,38 ha. A diminuição da área para a produção e a acumulação fundiária, acabou favorecendo alguns processos já existentes na região, principalmente a migração e o êxodo rural. Sem terra para trabalho e com os preços da terra cada vez mais altos, a alternativa dos agricultores de ida para o trabalho na colheita de cana, café e na construção civil se tornou cada vez mais constate (GALIZONI, 2013).

A dimensão cartográfica da área de vegetação preservada nos imóveis rurais está representada na Figura 4, sendo esta área de cor verde a área de vegetação preservada, e a área de cor cinza e preta outros tipos de áreas (área consolidada, interesse público, sede e infraestrutura). Á área de vegetação preservada é a junção das principais áreas 
vegetação dentro da propriedade, área de preservação permanente, área de reserva legal e área de vegetação nativa.

Figura 3 - Distribuição dos imóveis rurais de das cidades de Turmalina, Minas Novas, Itamarandiba, Veredinha, Capelinha, Carbonita e Aricanduva sobre a declividade DISTRIBUIÇÃO DOS IMÓVEIS RURAIS SOBRE A DECLIVIDADE

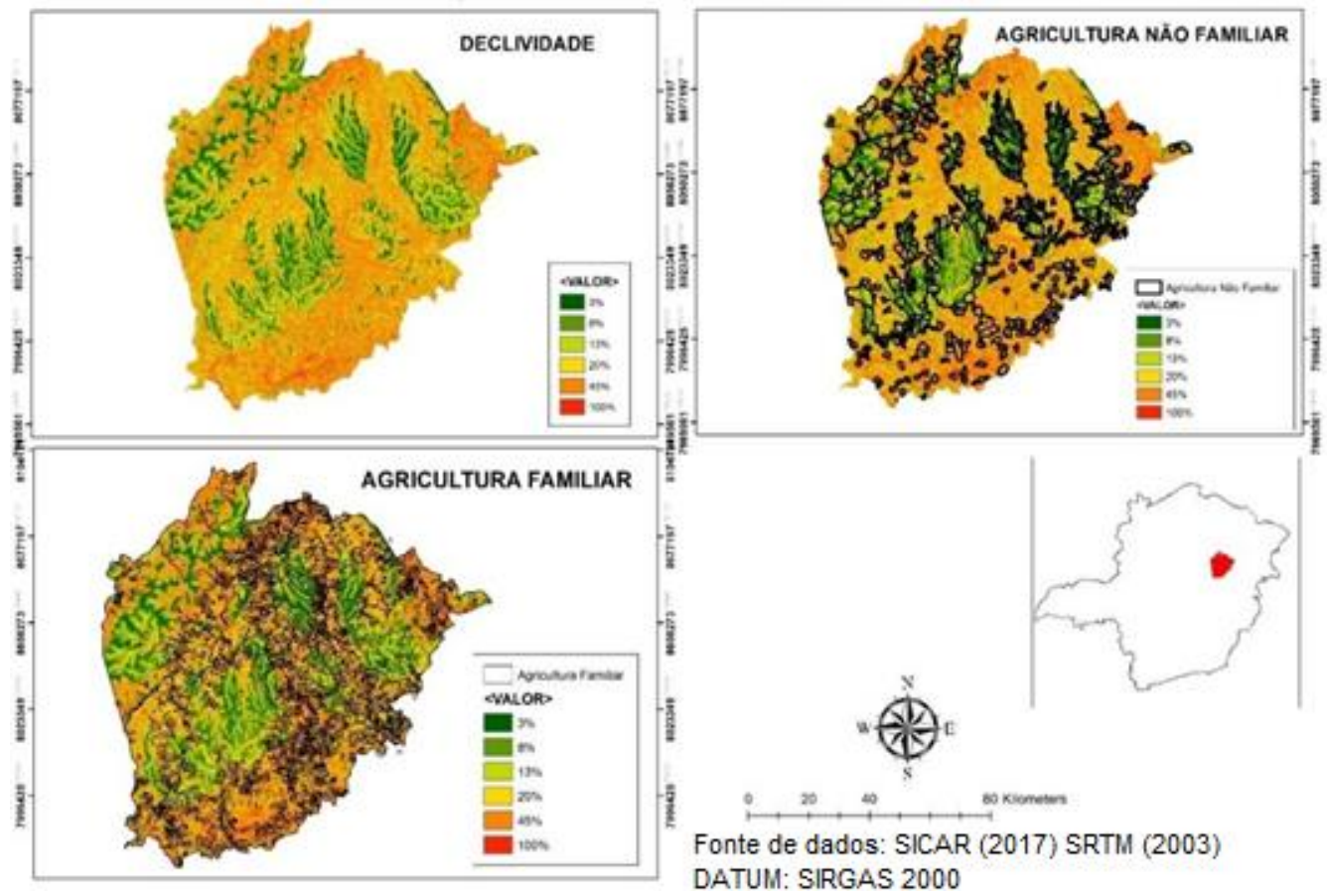

Fonte: (Autores, 2017)

Figura 4 - Áreas de Preservação Permanente das cidades de Turmalina, Minas Novas, Itamarandiba, Veredinha, Capelinha, Carbonita e Aricanduva sobre as propriedades rurais

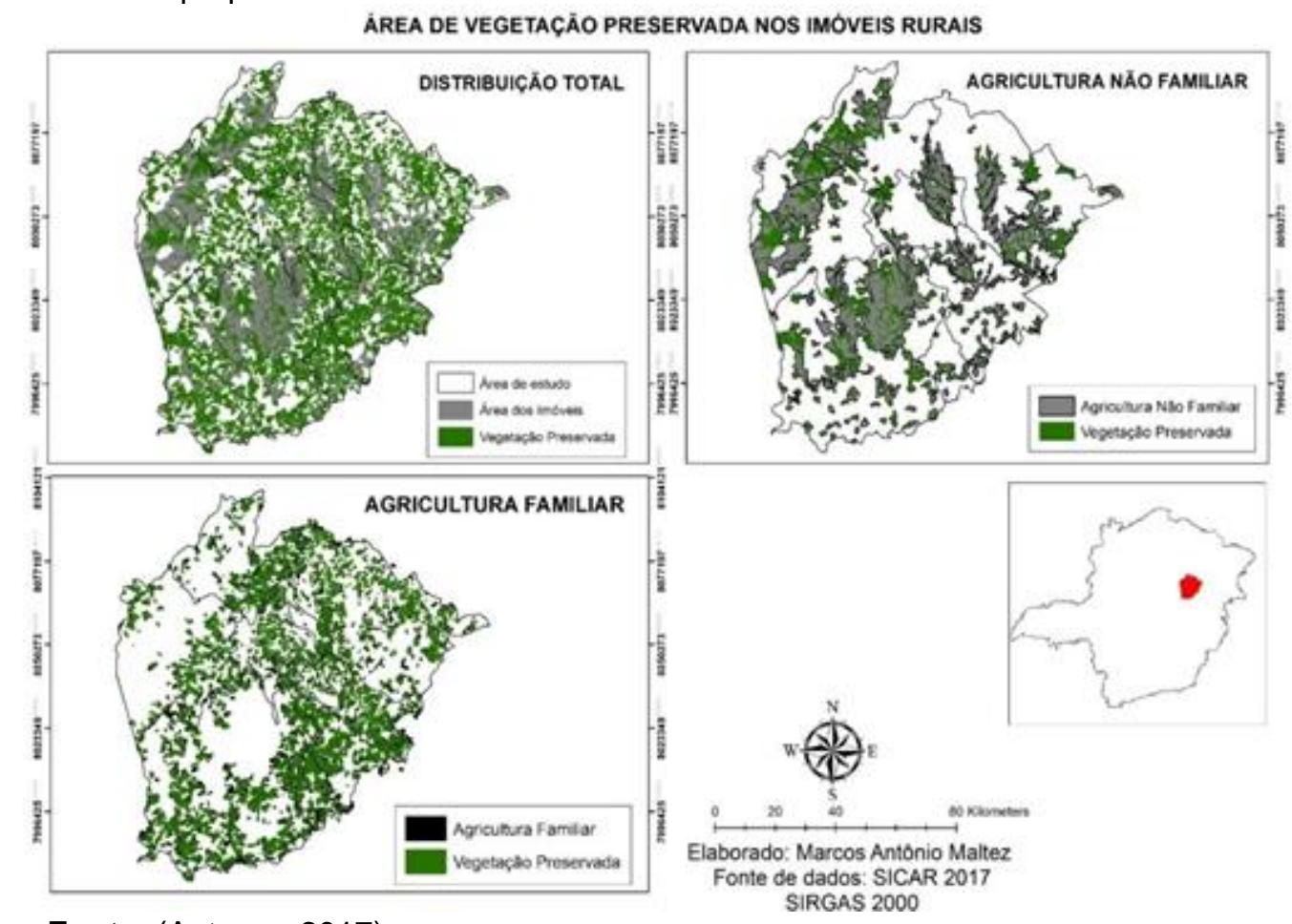

Fonte: (Autores, 2017) 
A região das chapadas e grotas do Alto Jequitinhonha conserva $51,13 \%$, da área cadastrada nos imóveis rurais, o que totaliza 364.000 dos 711.801 ha cadastrados. Não houve diferença significativa na área preservada entre agricultura familiar e não familiar. A agricultura familiar preserva um total de $170.180 \mathrm{ha}$, o que representa $52,36 \%$ da área total, enquanto que a agricultura não familiar preserva um total de 194.500ha o que representa $50,28 \%$ de área total.

No quadrante que representa a agricultura-não-familiar, é possível notar a presença de corredores verdes ou ecológicos, estes são feitos com o intuito de aumentar a habilidade de organismo da biodiversidade se locomoverem entre as extensas faixas de eucalipto que existem na região, essa ferramenta é obrigatória para os plantios, o que aumenta a área preservada de vegetação nativa (FONSECA et al., 2002). Outro fato que chama atenção e que a área preservada dentro dos imóveis da agricultura não familiar, ficam sempre dentro das chamadas grotas que cortam as chapadas, essas áreas não conseguem ser ocupadas por conta da sua declividade receber plantios comerciais.

Segundo os dados do CAR 2017, não existe déficit de vegetação nativa na região já que os imóveis rurais preservam acima do exigido por lei (BRASIL, 2012). Sendo que é importante salientar que apesar da preservação, a silvicultura ocupou uma extensa área que antes era do cerrado, causando impactos na biodiversidade e ciclo hidrológico da região (LIMA, 2013; SOUZA, 2014). O que não consegue ser recompensado a partir de técnicas de mitigação, como os corredores ecológicos, já que a grande maioria dessas áreas são recuperadas com espécies exóticas. Os dados corroboram com os trabalhos que vem sendo desenvolvidos pelo grupo GITE. O Brasil preserva em média 30\% de seu território, seja por meio de unidades de conservação, terras indígenas e áreas de preservação permanente e reserva legal presente dentro imóveis rurais (MIRANDA et al., 2016).

As nascentes da região se encontram principalmente nas chamadas grotas, onde estão principalmente os imóveis da agricultura familiar. A região tem um total de 1624 nascentes, sendo que $79 \%$ (1269) desse total se encontram nos terrenos da agricultura familiar, enquanto que apenas $21 \%$ (355) das nascentes se encontram nos imóveis da agricultura não familiar, como mostra a Tabela 2. 
Tabela 2 - Distribuição de nascentes de corpos hídricos dos Imóveis Rurais das cidades de Turmalina, Minas Novas, Itamarandiba, Veredinha, Capelinha, Carbonita e Aricanduva

\begin{tabular}{ccccc}
\hline Tipo de Imóvel & $\begin{array}{c}\text { Quantidade } \\
\text { de imóveis }\end{array}$ & $\begin{array}{c}\text { Área } \\
\text { (hectares) }\end{array}$ & $\begin{array}{c}\text { № de } \\
\text { nascentes }\end{array}$ & $\begin{array}{c}\% \text { de } \\
\text { nascentes }\end{array}$ \\
\hline $\begin{array}{c}\text { Agricultura } \\
\text { familiar }\end{array}$ & 8460 & $324.982,00$ & 1269 & $79 \%$ \\
$\begin{array}{c}\text { Agricultura } \\
\text { não familiar } \\
\quad \text { Total }\end{array}$ & 332 & $386.819,00$ & 355 & $21 \%$ \\
\hline & 8792 & $711.801,00$ & 1624 & $100 \%$ \\
\hline
\end{tabular}

A distribuição das nascentes nos imóveis rurais está representada na Figura 5, onde é possível notar a diferença existente entre a quantidade de nascentes presentes nos imóveis da agricultura familiar e não familiar.

Figura 5 - Nascentes de corpos hídricos das cidades de Turmalina, Minas Novas, Itamarandiba, Veredinha, Capelinha, Carbonita e Aricanduva sobre as propriedades rurais

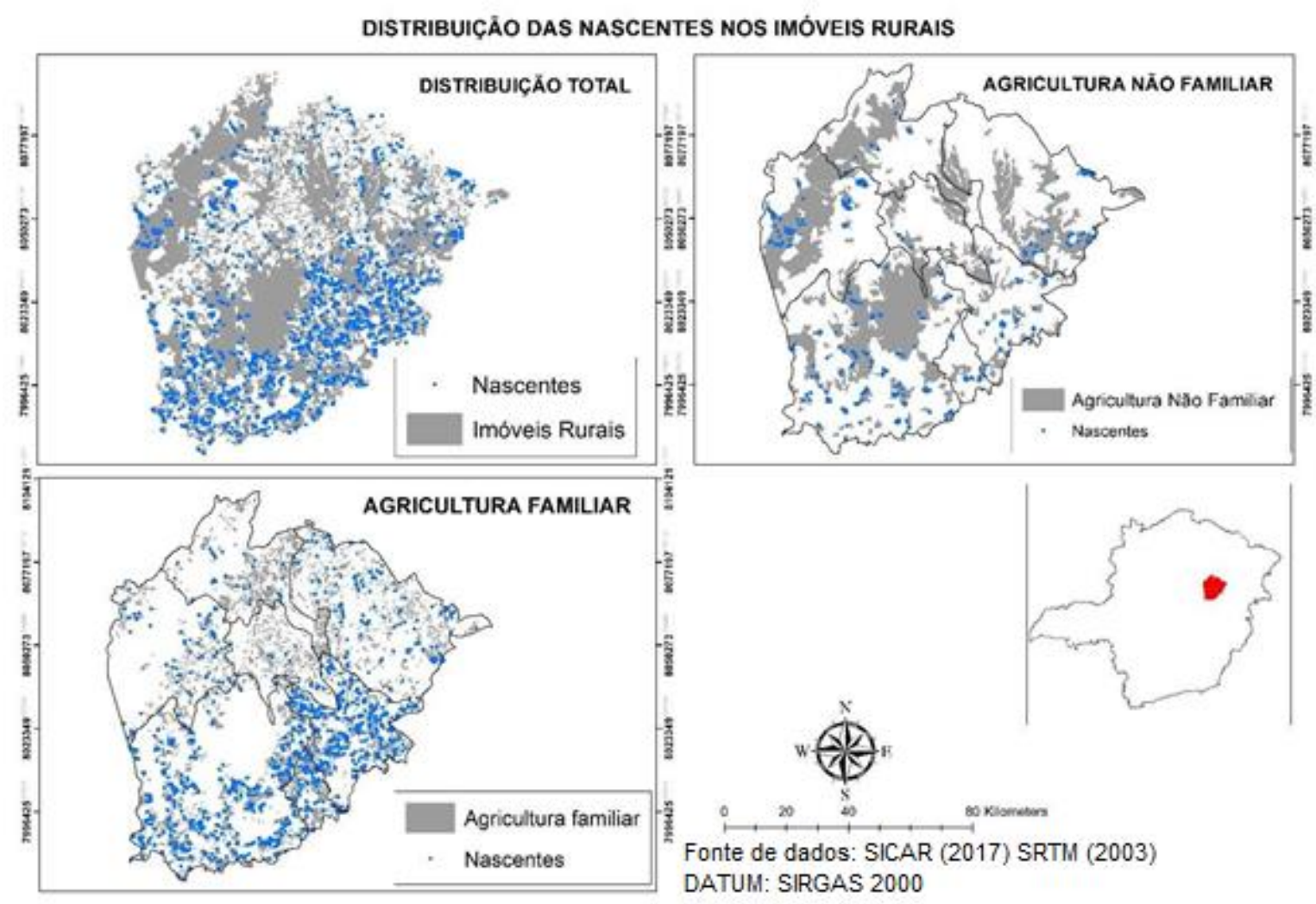

Fonte: (Autores, 2017)

A conservação das nascentes tornou-se foco prioritário principalmente a partir da implantação das monoculturas de eucaliptos na região, quando os agricultores familiares viram a vazão dos seus rios diminuírem e suas nascentes começarem a secar. Essa sensibilização nos cuidados das nascentes deu início na década de 1990 a um programa de recuperação e conservação das fontes naturais da região, que ficou conhecido como 
"cercamento comunitário de nascentes" (GALIZONI, 2013). Essa iniciativa tem como objetivo contribuir para preservação e recuperação das nascentes da região, reduzindo o desmatamento e a ação degenerativa do gado sobre as nascentes, o "cercamento" das nascentes e plantio de mudas acontece em forma de mutirão, onde cada família ajuda a outra na preservação das nascentes (GALIZONI, 2013).

De acordo com os dados do CAR de 2017, percebe-se que no Alto Jequitinhonha a agricultura familiar preserva cerca de $52,28 \%$ da sua área, os imóveis rurais desse segmento estão localizados nas grotas, onde a declividade vai de $20-100 \%$, o que se torna grande parte dessa área um local de preservação permanente, o que legitima esses números. Como o relevo do terreno da agricultura familiar não permite a implementação de grandes projetos agropecuários, a agricultura desenvolvida é de pequeno porte, como: hortas, agroflorestas, cultivos para subsistência, o que não exige grandes áreas para exploração.

Apesar de possui menor quantidade de nascentes, as chapadas são conhecidas como as caixas d água do cerrado, onde a água infiltra para ser devolvida a superfície pelas nascentes (LIMA; SILVA, 2007), o processo de ocupação das chapadas pelos eucaliptais diminuiu o volume e a quantidade de nascentes, já que o eucalipto por ser uma planta que se desenvolve com rapidez necessita de grande quantidade de água para o seu crescimento, é em comparação com cerrado exige quantidades maiores de água para o seu desenvolvimento causando assim um déficit hídrico (LIMA, 2013; LIMA, 2004). Os dados vão de encontro das diversas pesquisas que abordam a questão da água e nascentes na região, a agricultura familiar depende diretamente da água para sua reprodução e manutenção, o que criou uma relação de conservação dessas importantes fontes de água. A mobilização dos agricultores familiares vem tentando diminuir esse impacto sobre os recursos hídricos da região, o cercamento das nascentes vem dando resultados como demonstram os dados do CAR.

\section{CONCLUSÃO}

O Alto Jequitinhonha é uma região de agricultura familiar tradicional e numerosa, onde o relevo formado por chapadas e grotas determinou os diferentes processos de ocupação e uso dos solos na região. A chegada de grandes empreendimentos, principalmente o reflorestamento com eucalipto, alterou drasticamente a dinâmica da região, a partir dos dados do CAR foi possível observar as mudanças no uso e posse da 
terra, recursos hídricos e vegetação nativa. O processo de ocupação das chapadas alterou completamente a distribuição fundiária da região, aumentando o preço da terra, diminuindo a área de uso pela agricultura familiar e acentuando a desigualdade social já existente na região. O que foi vendido a população como esperança de desenvolvimento, trabalho e renda, se tornou um problema ambiental, social e econômico.

As informações disponibilizadas pelo CAR, são as mais recentes sobre a situação ambiental rural brasileira, e apesar de não ser o objetivo fim do CAR, os dados podem e devem ser utilizados para pesquisas de ordenamento territorial, questão fundiária, análise ambiental, recursos hídricos e interdisciplinares. Os mapas que são desenvolvidos permitem uma visualização dos diferentes recursos de cada município. Apesar das controvérsias existentes sobre a veracidade e legitimidade dos dados, o CAR é uma ferramenta complexa e possui um banco de dados muito vasto, diferente de tudo o que o Brasil já havia produzido, isso abriu um leque muito grande de conexões e possibilidades para pesquisas e análises em inteligência territorial e ambiental. Principalmente pelo cadastro ser feito por meio de geoprocessamento, o que possibilita a análise desses dados por diferentes softwares e metodologias, enriquecendo ainda mais as pesquisas.

\section{REFERÊNCIAS}

CALIXTO, J. Reflorestamento, terra e trabalho: análise da ocupação fundiária e da força de trabalho no Alto Jequitinhonha, MG. 2006. 130. Dissertação (Mestrado em Administração) Departamento de Economia e Administração, UFLA, Lavras, 2006.

COMISSÃO DE DESENVOLVIMENTO DO VALE DO JEQUITINHONHA. Prédiagnóstico do Vale do Jequitinhonha, v. I e II. Edição do Governo de Minas Gerais, Belo Horizonte,s/d.

EMPRESA BRASILEIRA DE PESQUISA AGROPECUÁRIA- EMBRAPA. Classificação da declividade do solo (Rio de Janeiro, RJ). Súmula da 10. Reunião Técnica de Levantamento de Solos. Rio de Janeiro, 1995. 83p. (EMBRAPA-SNLCS).

FONSECA, G.A; ALGER, K; PRINTO, L.P; ARAÚJO, M; CAVALCANTI, R. Corredores Ecológicos da Biodiversidade: o corredor central da Mata Atlântica. In: SEMINÁRIO SOBRE CORREDORES ECOLÓGICOS NO BRASIL, 1., 2002. [Anais ...] I Coordenação Geral a de Ecossistemas - IBAMA, 2002.

GALIZONI, F. M. Lavradores, águas e lavouras: estudos sobre gestão camponesa de recursos hídricos no Alto Jequitinhonha. Belo Horizonte: Ed. UFMG, 2013. 254 p. V.1

GALIZONI, F. M. Terra, ambiente e herança no alto Jequitinhonha, Minas Gerais. Revista de

Economia e Sociologia Rural, Brasília, v. 40, n.3, p. 77-96, mar. 2002.

https://doi.org/10.1590/S0103-20032002000300003 
GALIZONI, F. M.; RIBEIRO, E. M. As águas da comunidade representações simbólicas da água em populações rurais de diferentes regiões de Minas Gerais. In: CONGRESSO BRASILEIRO DE ECONOMIA E SOCIOLOGIA RURAL, 41., 2003, Juiz de Fora. [Anais...]. Brasília: Sociedade Brasileira de Economia e Sociologia Rural, 2003. p. 528-548

GEARY, R. C. The contiguity ratio and statistical mapping. Incorporated Statistian, v. 5 p. 115145, 1954. https://doi.org/10.2307/2986645

IBGE. Cidades. Disponível em: www.ibge.com.br. Acesso em: 19 fev. 2018

IBGE. Classificação e caracterização dos espaços rurais e urbanos do Brasil : uma primeira aproximação / IBGE, Coordenação de Geografia. - Rio de Janeiro: IBGE, 2017. 84p

LEITE, A.C. G. A modernização do Vale do Jequitinhonha mineiro e o processo de formação do trabalhador "boia fria" em suas condições regionais de mobilidade do trabalho. São Paulo, 2010. Dissertação (Mestrado em Geografia) - Departamento de Geografia da Faculdade de Filosofia, Letras e Ciências Humanas da Universidade de São Paulo. São Paulo, 2010.

LIMA, J. E. F. W.; SILVA, E. M. "Estimativa da contribuição hídrica superficial do Cerrado para as grandes regiões hidrográficas brasileiras". In: SIMPÓSIO BRASILEIRO DE RECURSOS HÍDRICOS, 17., 2007. [Anais...]. São Paulo: ABRH, 2007.

LIMA, V, M, P. Secas e Águas. Alterações na dinâmica da água no Alto Jequitinhonha. In: GALIZONI. F, M. Lavradores, Águas e Lavouras: estudos sobre gestão camponesa de recursos hídricos no Alto Jequitinhonha.1. ed. Belo Horizonte, 2013. p. 99-124

LIMA, W. P; ZAKIA, M. J. B. As florestas plantadas e a água: implementando o conceito da microbacia hidrográfica como unidade de planejamento. São Carlos: Ed. RIMA, 2006. 226p.

LIMA, W. O eucalipto seco o solo. Sociedade Brasileira de Ciências do Solo, v. 29, n. 1, jan. 2004.

MAZOYER, M.; ROUDART, L. História das agriculturas no mundo: do neolítico à crise contemporânea. São Paulo: Ed UNESP; Brasília, v.1, 2010. 568 p.

MIRANDA, E. E. de; CARVALHO, C. A. de; OSHIRO, O. T.; MARTINHO, P. R.

R. Agricultura e preservação ambiental no Brasil: primeira análise do cadastro ambiental rural. Disponível em: https://www.cnpm.embrapa.br/projetos/car/. Acesso em: 10 de out. 2017.

RIBEIRO, A. E. M.; GALIZONI, F. M. Sistemas agrários, recursos naturais e migrações no alto Jequitinhonha, Minas Gerais. In: TORRES, Haroldo; COSTA, Heloísa. (Org.). População e meio ambiente: debates e desafios. São Paulo: Ed. SENAC, v.1, 2000. p. 163-189.

RIBEIRO, E. M; M; SILVESTRE; S; ASSIS, T. R; BARBOSA, E. C. A. Agricultura familiar e programas de desenvolvimento rural no alto Jequitinhonha. Revista de Economia e Sociologia Rural, v. 45, p. 809-836, 2007. https://doi.org/10.1590/S0103-20032007000400012

SABATER, L. A.; TUR, A. A.; AZORÍN, J. M. N. Análise Exploratória dos Dados Espaciais. In: COSTA, J. S.; DENTINHO, T. P.; NIJKAMP, P. Compêndio de Economia Regional: métodos e técnicas de análise regional. v. 2. Ed. Principia, p. 237-298, 2011.

SERVIÇO NACIONAL DE APRENDIZAGEM RURAL. A proteção de nascentes em cinco passos. Programa Campo Sustentável - Curso de Proteção de Nascente. Brasília, 2015.

SICAR- SISTEMA NACIONAL DE CADASTRO RURAL. Disponível em: 
www.car.gov.br/publico/imoveis. Acesso em: 16 ago. 2017.

SILVA, F. D. Sistemas agrários e agricultura no Alto Jequitinhonha, 2014, 241 p. Tese (Doutorado em Extensão Rural) - Universidade Federal de Santa Maria, Santa Maria, 2014.

SILVA, J. X; ZAIDAN, D. S. J. Geoprocessamento e análise ambiental: aplicações. 1. ed. Rio de Janeiro: Bertrand Brasil, v. 1, 2004. 368p.

SILVA, J, X. Geoprocessamento para análise ambiental. 1. ed. Rio de Janeiro: D5, v. 1, 2001. $228 \mathrm{p}$.

SOUZA, N. F. O cadastramento ambiental rural: sua origem e o dever de instituição pelos Estados. In: CONGRESSO NACIONAL DOS PROCURADORES DE ESTADO, 39., 2013.

[Anais...]. Porto de Galinhas, 2014.

TOPODATA. Disponível em: www.topodata.com.br. Acesso em: 16 set. 2017.

VITAL, M. H. F. Impacto ambiental de florestas de eucalipto. Revista do BNDES, Rio de Janeiro, v. 14 , n. 28, P. 235-276, dez. 2007. Disponível em:

http://www.bndes.gov.br/SiteBNDES/export/sites/default/bndes pt/Galerias/Arquivos/conheciment o/revista/rev2808.pdf. Acesso em: 20 dez. 2017.

VOLPATO, M. M. L; ALVES, H. M. R; VIERIA, T. G. C. Geotecnologias aplicadas a meteorologia. Informe Agropecuário, Belo Horizonte, v.29, n. 249, p. 1-10, 2008. 